\title{
Characteristics of Bayern fluid inclusions
}

Rong $\mathrm{Ye}^{1} *$ Youmin $\mathrm{Bai}^{2}$

${ }^{1}$ School of Earth Sciences and Resources, China University of Geosciences, Beijing 100083, China

${ }^{2}$ School of Earth Sciences and Resources, China University of Geosciences, Beijing 100083, China

We studied some fluid inclusion samples collected from Bayern, and the results are as follows.

The samples in the first stage were mainly from quartz veins. A total of 74 inclusions were tested in this stage. The inclusions are mostly liquid-rich inclusions and three-phase $\mathrm{CO}_{2}$ inclusions. The shape of the inclusions is irregular, oval. The long axis is concentrated at $5-20 \mu \mathrm{m}$, and the gas phase fraction is generally $5 \%-20 \%$. Uniform temperature range: $181-361^{\circ} \mathrm{C}$, salinity range:0.41-15.00\%, density range: $0.71-1.11 \mathrm{~g} / \mathrm{cm}^{3}$.

The samples in the second stage mainly also came from quartz veins. 118 inclusions were analyzed at this stage, which are gas-liquid two-phase inclusions. Most of the inclusions are irregular and long, and the size varies from 6 to $10 \mu \mathrm{m}$. The gas phase fraction is generally between $2 \%-20 \%$.Uniform temperature range: $124-321^{\circ} \mathrm{C}$, salinity range:1.39-8.13\%, density range: $0.75-0.96 \mathrm{~g} / \mathrm{cm}^{3}$.

The samples in the third stage mainly came from the symbiotic quartz veins of Galena. In this stage, We studied 38 samples, which were gas-liquid two-phase inclusions. The inclusions were mostly irregular and elliptical, with the long axis concentrated at $7-23 \mu \mathrm{m}$, gas phase fraction is generally $2 \%-15 \%$.Uniform temperature range: 150 $-293{ }^{\circ} \mathrm{C}$, salinity range: $1.39-6.58 \%$, density range:0.76-0.94 $\mathrm{g} / \mathrm{cm}^{3}$.

The samples in the fourth stage were mainly from the rich liquid inclusions of fluorite. A total of 73 samples were tested in this stage. The inclusions are mostly oval and irregular, with the long axis concentrated at $7-40 \mu \mathrm{m}$, and the gas phase fraction is generally $2 \%-20 \%$.Uniform temperature range: $113-246^{\circ} \mathrm{C}$, salinity range: $1.05-7.58 \%$, density range:0.85-0.96 $\mathrm{g} / \mathrm{cm}^{3}$.

The conclusion is that we think of Bayern as a mesothermal hydrothermal deposit. 